This item was submitted to Loughborough's Research Repository by the author.

Items in Figshare are protected by copyright, with all rights reserved, unless otherwise indicated.

\title{
Connecting wearable textile transmission lines: all-textile fabrication solutions and design techniques
}

\section{PLEASE CITE THE PUBLISHED VERSION}

http://dx.doi.org/10.1049/el.2015.1623

\section{PUBLISHER}

(c) The Institution of Engineering and Technology

\section{VERSION}

AM (Accepted Manuscript)

\section{PUBLISHER STATEMENT}

This work is made available according to the conditions of the Creative Commons Attribution-NonCommercialNoDerivatives 4.0 International (CC BY-NC-ND 4.0) licence. Full details of this licence are available at: https://creativecommons.org/licenses/by-nc-nd/4.0/

\section{LICENCE}

CC BY-NC-ND 4.0

\section{REPOSITORY RECORD}

Tsolis, Aris, Antonis A. Alexandridis, W.G. Whittow, and J.C. Vardaxoglou. 2019. "Connecting Wearable Textile Transmission Lines: All-textile Fabrication Solutions and Design Techniques”. figshare. https://hdl.handle.net/2134/20202. 


\section{Connecting wearable textile transmission lines: all-textile fabrication solutions and design techniques}

A. Tsolis ${ }^{\bowtie}$, A.A. Alexandridis, W.G. Whittow and J.C. Vardaxoglou

A new method for connecting transmission lines is presented withou using rigid connectors in order to implement a fully textile interconnecting system appropriate for signal transmission in wearable applications. This method is applied to textile striplines and named 'complementary overlap'. The proposed method is examined from 1 to $6 \mathrm{GHz}$ covering the frequency bands of the target applications: ISM (WLAN, Bluetooth, ZigBee etc.) and L-band (GPS).

Introduction: Wearable antennas and electronics could be the future of smart garments [1]. Current wearable communication systems use rigid connectors (e.g. coaxial SMA connectors). Connection methods that could lead to the exclusion of rigid cables and connectors were proposed and investigated in our previous work [2]. That work yielded 'complementary overlap' $(\mathrm{CO})$ as the most promising connection method in terms of performance and implementation simplicity. This method is examined in the present Letter regarding fabrication hints and prototyping issues for alltextile implementation. More specifically, this Letter focuses on the selection of the fabrication materials emphasising the adhesive materials used for the assembly of the transmission line (TL). In addition, a ground plane structure modification is presented which improves the connection performance by minimising the effect of the geometrical ambiguities.

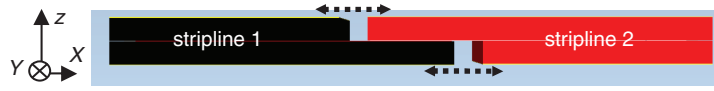

Fig. 1 Schematic of CO concept

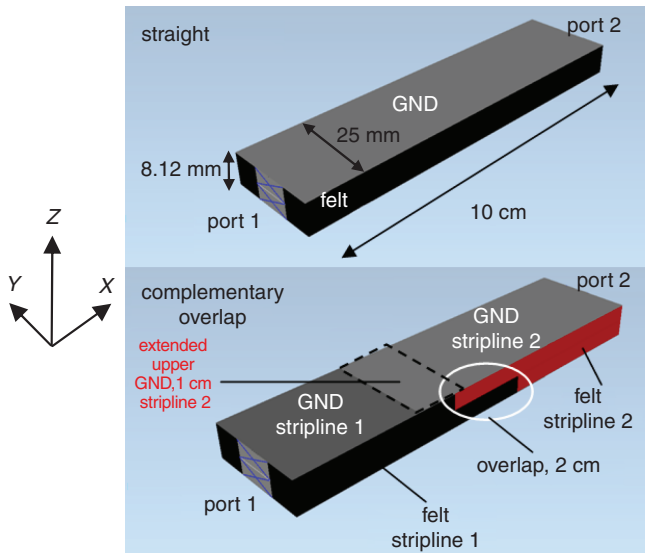

Fig. 2 Textile stripline models: ST and CO

Geometry of all-textile stripline connection method: The concept of the CO connection method is shown in Fig. 1. Both striplines use felt as a dielectric substrate. To evaluate the proposed stripline connection method a 'straight' (ST) stripline [3] was fabricated and used as the reference. The models and prototypes of the ST and the CO TLs are shown in Fig. 2 and 3.

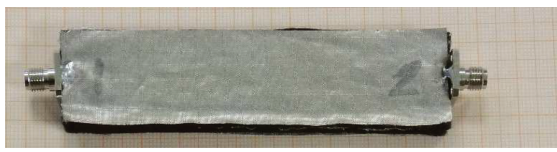

a

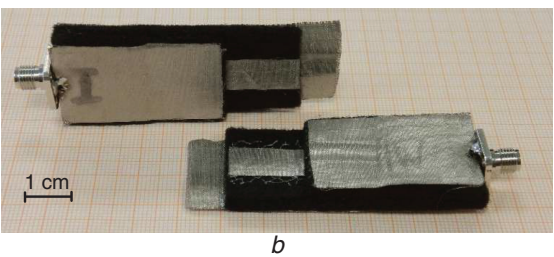

Fig. 3 Fabricated fully textile: ST (Fig. 3a) and CO (Fig. 3b) stripline connection scenarios
Materials used: The materials used to fabricate the textile TL models were: felt as the dielectric substrate and Nora-Dell fabric as the conductive textile cloth [4]. Three different methods of attaching Nora-Dell to felt were examined: (i) a universal adhesive (UHU glue); (ii) a fusible adhesive that is designed to be used to hem garments (Hemming-web) and (iii) sewing (by using non-conductive thread).
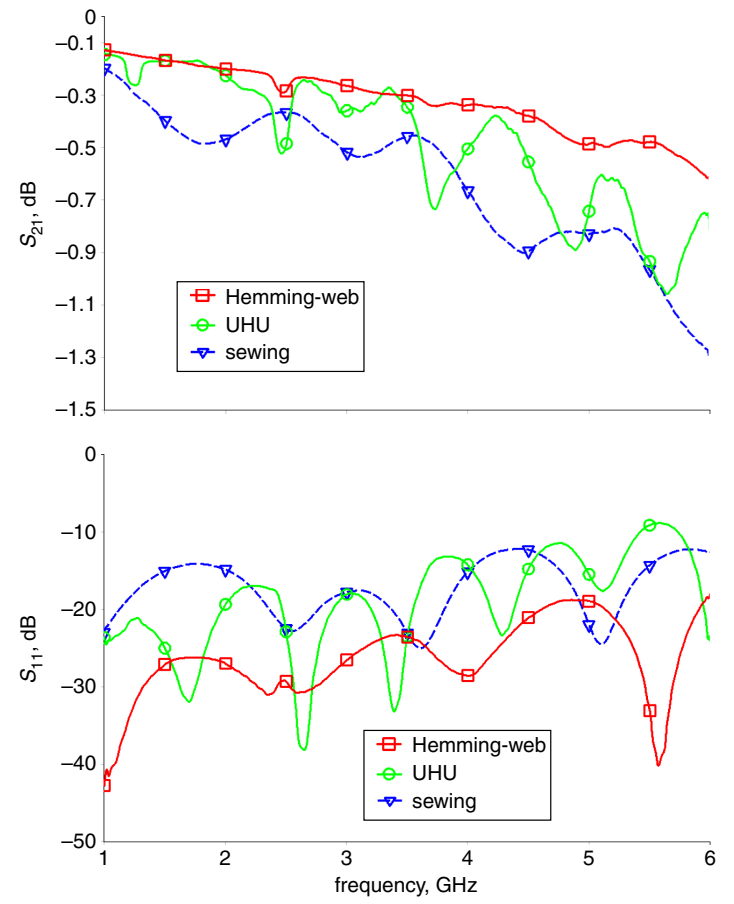

Fig. $4 S_{21}$ and $S_{11}$ measurement results of ST with Nora-Dell

To assess which method yields the best performance, three ST prototypes using these three methods of attaching Nora-Dell to felt were constructed. The measured $S_{21}$ and $S_{11}$ of the ST prototypes are presented in Fig. 4. The case of Hemming-web yields the best $S_{21}$ performance. It has lower losses than the UHU glue and the sewed cases. Hemming-web has the lowest $S_{11}$ for the examined frequency range $(1-6 \mathrm{GHz})$ Another issue that has to do with the conductive textile cloth (Nora-Dell) is its performance in comparison to copper tape which was used as the pilot conductive material in our previous work [2]. Copper tape has higher conductivity and lower ohmic losses than Nora-Dell $[1,2]$. The minimum measured $S_{21}$ value of an ST copper tape $10 \mathrm{~cm}$-long stripline [2] is equal to $-0.5 \mathrm{~dB}$ and the respective Nora-Dell is equal to $-0.6 \mathrm{~dB}$ (Hemming-web case, Fig. 4). Based on the above, it can be stated that use of Hemming-web is the most promising in terms of losses compared with the other two examined cases. Moreover, in the Nora-Dell/Hemming-web cases the losses increase by $0.1 \mathrm{~dB}$ compared with the copper tape one. However, the Nora-Dell prototype is more appropriate than the copper tape for alltextile wearable applications [2].

$\mathrm{CO}$ - ground plane extension: In our previous work [2], the effect of geometrical discontinuities on $\mathrm{CO}$ scenario performance was examined. The geometrical discontinuities at the connection end of the two individual TLs which structure the CO were modelled as parameters: $D_{x}, D_{y}$ and $D_{z}$ in the three axes of the coordinate system (Fig. 5). It was proved that the $S_{21}$ performance of the CO is highly affected by the geometrical discontinuities. To ensure better signal transmission in case geometrical discontinuities occur while connecting both stripline parts of the CO structure the ground planes of the longest side (GND) of both individual stripline parts were extended (Fig. 5). The simulated $S_{21}$ results for the $D_{x}, D_{y}$ and $D_{z}$ values for the extended ground planes are shown in Fig. 6. In Fig. 6, the corresponding $S_{21}$ simulation results for the non-extended ground planes (GNDs) [2] model are presented. 


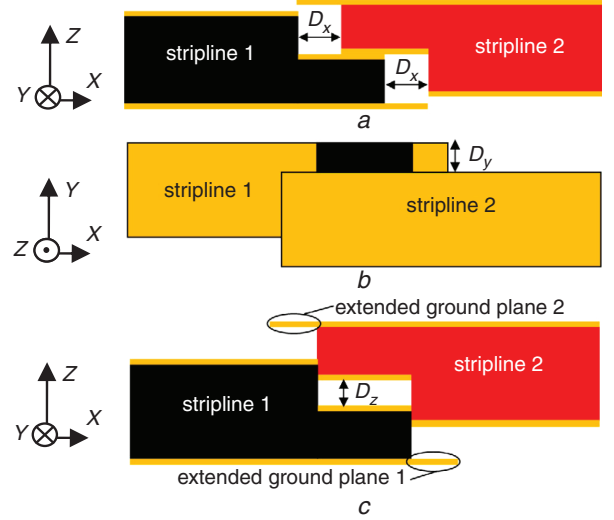

Fig. 5 Schematic of CO geometrical discontinuities: $D_{x}$ (Fig. 5a), $D_{y}$ (Fig. $5 b)$, and $D_{z}$ (Fig. 5c) with extended ground planes

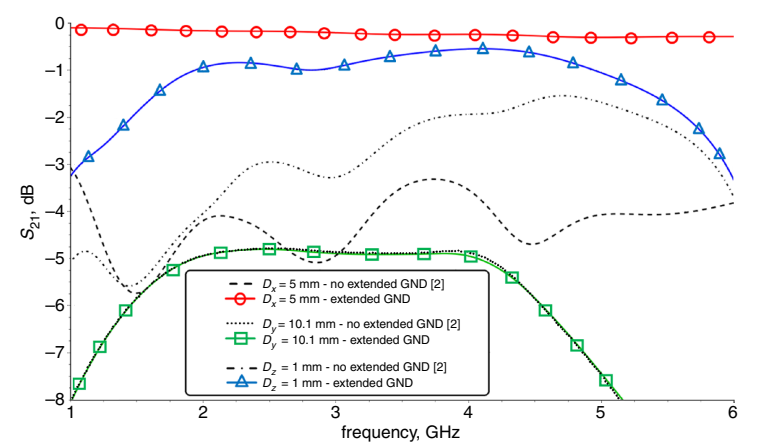

Fig. $6 S_{21}$ simulation results of $\mathrm{CO}$ discontinuity parameters with and without extended ground plane

It can be concluded that $S_{21}$ is improved by the extension of the GNDs in the case of $D_{x}$ and $D_{z}$. The choice of enhancing the CO by extending the GND planes improves the TL performance by minimising the effect of possible connection discontinuities.

CO versus ST: To facilitate the measurement of the CO prototype, clamps were used to keep the two stripline individual parts of the $\mathrm{CO}$ firmly connected (Fig. 7). In terms of final wearable realisation another more practical and wearable solution must be found (e.g. conductive Velcro or magnets).

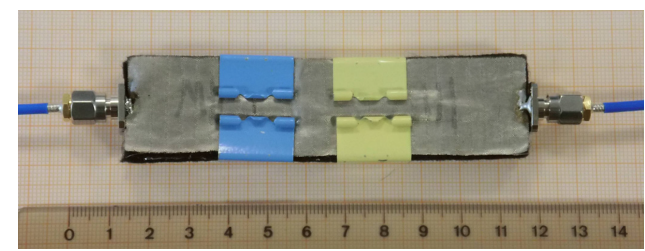

Fig. 7 CO modification for $S_{21}$ measurement

The $S_{21}$ and the $S_{11}$ measurement results for the cases of CO and ST are shown in Fig. 8. CO yields $S_{21}$ better than $-2 \mathrm{~dB}$. The nulls in the $S_{21}$ could be due to the pressure applied from the connecting clamps. The height of the dielectric is changing and this affects the line impedance which increases the losses and initiates standing waves [3]. Finally, both prototypes (ST and $\mathrm{CO}$ ) yield $S_{11}$ lower than $-10 \mathrm{~dB}$. The maximum transmission loss in the examined frequency range for the $10 \mathrm{~cm}$ ST stripline case is $0.5 \mathrm{~dB}$ and for the same TL length with the $\mathrm{CO}$ connection it is $1.8 \mathrm{~dB}$. The losses that the $\mathrm{CO}$ connection inserts are obviously larger than those of an SMA connector. However, the all-textile $\mathrm{CO}$ can be easily incorporated into garments, becoming a flexible solution for interconnecting textile wearable antennas and electronics. It is proven that a stripline transmission yields significantly less losses than a wireless non-line-of-sight on-body communication link [5]. Therefore, the $\mathrm{CO}$ can be used efficiently in such a communication link, e.g. chest to back on-body communication path.
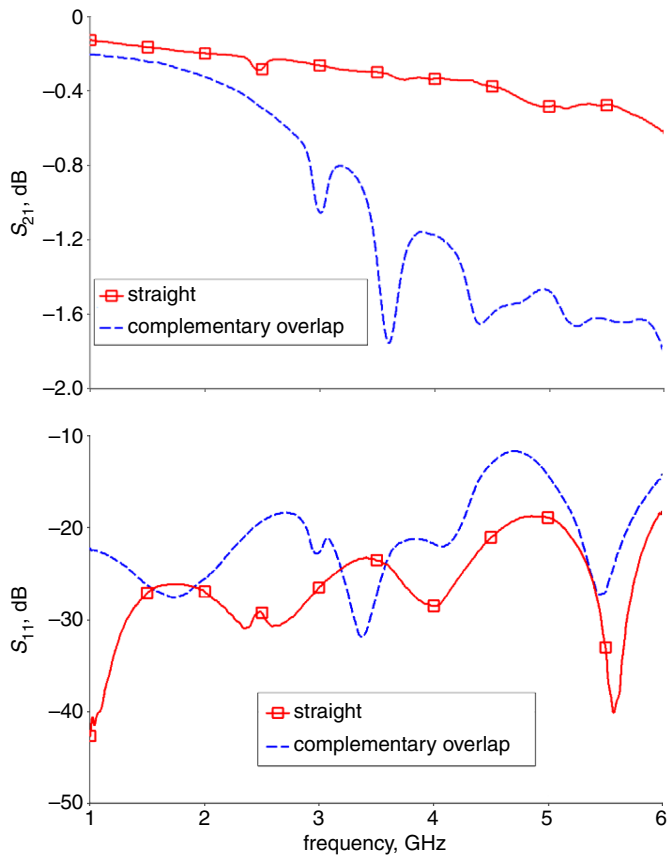

Fig. $8 S_{21}$ and $S_{11}$ measurement results of $S T$ and CO textile striplines

Conclusion: It has been demonstrated via measurements that Hemming-web compared with UHU glue and sewing (with nonconductive yarn) is the most appropriate method, in terms of losses, in order to attach the conductive with the dielectric cloth so as to assemble an all-textile stripline structure. It is also proved that the extension of the GND planes of the two individual parts of the $\mathrm{CO}$ connection improves the $S_{21}$ in case discontinuities occur. It is concluded from measurements on a $10 \mathrm{~cm}$-long TL structure that the $S_{21}$ is higher than $-2 \mathrm{~dB}$ and the $S_{11}$ is lower than $-10 \mathrm{~dB}$ in the examined frequency range $(1-6 \mathrm{GHz})$. The CO connection technique will enable a flexible interconnection method between wearable antennas and electronics.

(C) The Institution of Engineering and Technology 2015

Submitted: 11 May 2015

doi: $10.1049 /$ el.2015.1623

One or more of the Figures in this Letter are available in colour online.

A. Tsolis, W.G. Whittow and J.C. Vardaxoglou (School of Electronic, Electrical and Systems Engineering, Loughborough University, Ashby Road, Loughborough, LE11 3TU, United Kingdom)

凶 E-mail: A.Tsolis@lboro.ac.uk

A.A. Alexandridis (Institute of Informatics and Telecommunications, National Centre for Scientific Research 'Demokritos', Athens, 15310 Greece)

A. Tsolis: Also with the Institute of Informatics and Telecommunications, National Centre for Scientific Research 'Demokritos', Athens, Greece

\section{References}

1 Hall, P., and Hao, Y.: 'Antennas and propagation for body-centric wireless communications' (Artech House, London/Boston, 2006, 1st edn)

2 Tsolis, A., Alexandridis, A.A., Whittow, W.G., and Vardaxoglou, J.C. 'Investigation of textile striplines connectivity for feeding and connecting wearable antennas'. European Conf. on Antennas and Propagation (EuCAP), Lisbon, Portugal, April 2015

3 Pozar, D.M.: 'Microwave engineering' (Wiley, Danvers, MA, USA, 2012, 4th edn)

4 Nora-Dell: http://www.statex.biz/index.php/en/2012-04-06-13-28-47/ item $/ 159$-shieldex\%C2\%AE-gewebe, accessed May 2015

5 Bai, Q., Swaisaenyakorn, S., Lee, H.-J., Ford, K.L., Batchelor, J.C., and Langley, R.J.: 'Investigation of a switchable textile communication system on the human body', Electronics, 2014, 3, (3), pp. 491-503 